\title{
Einige Beobachtungen über die Eigenart der Canace
} ranula Loew.

\author{
Von G. Gercke in Hamburg.
}

(Mit Holzschnitt.)

In der „Berl. Entomol. Zeitschr.", 18. Jahrgang (1874), pag. 76-82, beschrieb H. Loew die von allen Ephydrinen interessanteste Gattung Canace, und zwar die der englischen Küste angehörige Art: C. nasica Hal. (Ann. Nat. Hist. III, 411; W alk er Brit. Dipt. II, 269), sowie eine andere, aber von Haliday nicht unterschiedene, auch der deutschen Nordseeküste eigene, welche er Can. ranula benannte.

Da L o ew am Schlusse seiner Monographie andeutet, für seine Untersuchungen nur über trockene Exemplare (vielleicht gar unkenntlich eingetrocknete, was die subtileren Theile anbeiangt) verfügt $\mathrm{zu}$ haben, so ist es erklärlich, wie sich seinem sonst so geübtem Blicke das Wesentlichste dieser Gattung die aussergewöhnliche Rüsselform - gänzlich hat entziehen können! *)

Es sei mir deshalb vergönnt, das Fehlende nachträglich aus jüngster eigener Erfahrung zu ergänzen, wornach dieser eigenartigen Fliege eine Sonderstellung in der Reihe der Ephydrinen gebührte.

Für Interessenten gebe ich zuvor in Nachstehendem das Locale zur Orientirung, da Canace nicht unmittelbar am fluthbewegten Strande zu suchen ist und ihre eigentlichen Stände nicht immer leicht zu finden sein dürften.

Zu Ende August d. J. hatte ich Gelegenheit, bei Ording, im Eiderstett'schen an der äussersten Südwestküste Schleswigs,

*) Befremdlich jedoch ist es, dass $\mathrm{H}$ a $\mathrm{l}$ i d a $\mathrm{y}$, welchem doch weit reichlicheres und frisches Material zu Gebote gestanden, dieses wichtige Factum nicht erkannt zu haben scheint, wie aus der Loew'schen Arbeit, welcher die H a l i d a y'sche zu Grunde lag, zu folgern ist, da L o e w nichts darauf Bezügliches reproducirt. Ich habe die Schrift und Illustration von H a li d a y leider nicht einsehen können. 
den öden Strand mit den Watten auf Dipteren abzusuchen, im besonderen mein Augenmerk auf Canace richtend, doch vergebens. Ausser einzelnen Fucellien ( $F$. fucorum Fall.) fand ich nur noch, stellenweise sogar reichlich, die schöne Scatella aestuans $\mathrm{H}$ a 1., meist an gestrandeten zerfliessenden Quallen, vor.

An dieser besonders exponirten Küstenecke haben die Hochfluthen den weissen Flugsand, ausserhalb den Schutzdeichen, $\mathrm{zu}$ in südlicher Richtung wandernden Dünen aufgethürmt; im Schutze dieser Dünenreihe, welche durch Anpflanzung von Strandhafer einige Stabilität erlangt hat, streckt sich ein begrastes Thal mit Tümpeln brackig gewordenen Regenwassers, und hier fand ich endlich an einer grasfreien, sandigen, abgeflachten Uferstelle eine Anzahl dieser zarten, sehr flüchtigen Canace ranula, deren räthselhaftes Treiben an der Wasserfläche auffallen musste.

In zierlichen, lebhaften Evolutionen durchfurchten sie im Fluge, hier und da auch ein Pärchen in Copula, den Wasserspiegel mit fast demselben Effect, wie ihn der luftführende Taumelkäfer (Gyrinus) unter Wasser hervorbringt. Sie erglänzten ebenso, doch nur, indem sie ein Luftbläschen an der Oberfläche hinführten, gewissermassen darauf schwebend. Mit Mühe nur gelang es mir eine geringe Anzahl dieser scheuen Geschöpfe zu haschen und im Fangnetze zwischen Grashalmen unbeschadet heimzutragen, um sie später am Fenster einzeln aufzufangen.

Nach genauerer Prüfung der Mundtheile stellte sich die überraschende Thatsache heraus, dass dieselben im Ganzen einen Hamen bilden, womit diese Fliegen nach Nahrung im Wasser fischen. In Bestätigung dessen fand ich später wiederholt im Darme und auch im Schlunde (bei einem eiertragenden ㅇ in sehr beträchtlicher Anzahl) Diatomeen: z. B. Cocconema, Gomphonema, seltener Bacillarien. Die Canace wird wohl auch auf Infusorien Jagd machen.

Betrachtet man den nach rückwärts geneigten Kopf, wie nachstehende Zeichnung ihn darstellen soll, so sieht man in eine tiefe, trichterförmige Oeffnung des Rüssels, dessen vorn tief ausgeschnittene, massive und breitgewölbte Unterlippenplatte mit einer durchsichtigen, zu einem Beutel vertieften Haut bekleidet ist. Dieser mit Wimpern umsäumte Beutel ist von einem querlaufenden Muskelbändchen gestützt, welches durch 
kräftige Muskeln regiert wird. Die Rüsselöffnung wird rechts und links von je einem Paar wulstiger Labellen begrenzt; hieran fügt sich, auf starken Muskeln spielend, jederseits ein Bündel leichtgekrümmter Gräten oder Borsten, deren oberste, stärkste auch noch einseitig gefiedert, d. h. spatelförmig geschuppt ist; diese beiden Bündel lassen sich, wenn herausgestreckt, fächerartig ausspreizen, andernfalls auch einklappen, wobei sie unter dem weitvorragenden und breiten Clypeus fast verschwinden, wo dann die Spitzen der zarten, blassen Taster sichtbar werden.

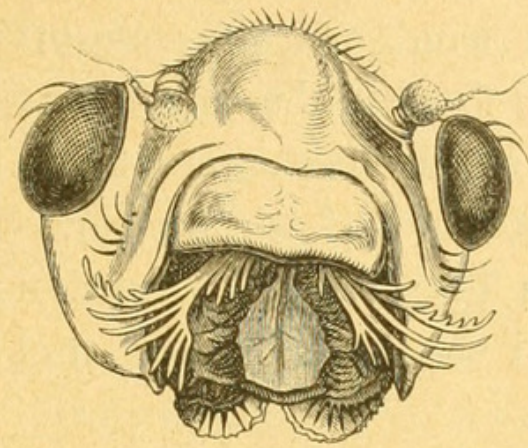

$\mathrm{Ob}_{\Rightarrow}=$ dieser Doppelfächer als Strudelapparat (nach Art wie bei gewissen Nematocerenlarven: Culiciden, Dixen, Simulien) $\mathrm{zu}$ functioniren hat oder ob er nur Luftfänger ist, bleibt einstweilen unentschieden, auch ob die Wimpern des Beutels oscilliren?

Da die ganze Gesichtshälfte des Kopfes als: Vorderstirn, Clypeus, Wangen und Backen, mit einem wasserdichtem Toment bedeckt ist, so haftet die mitgeführte Luftblase um so fester.

In der Einleitung seiner Arbeit, pag. 76, vindicirt Lo ew der Gattung Canace eine dritte Basalzelle, indem die obere, längere, durch eine deutliche Querader halbirt wird. Can. nasica kenne ich nicht, finde aber bei einem vollen Dutzend C. ranula nur an einer einzigen, und zwar auch nur an einem ihrer Flügel diese Abnormität, während der andere Flügel und sämmtliche sonst normal sind. Es wird sich hierbei wohl nur um ein wiederholt vorkommendes Naturspiel handeln. Eine Eigenthümlichkeit der Flügel ist, dass die Randader zuerst bis zur Mündung der ersten Längsader ganz nackt, dann auf dem langen Raum bis zur Mündung der zweiten Längsader 
dicht gedörnelt, hierauf bis zum Ende, d. h. bis zur Mündung der vierten Längsader wieder nackt ist.

In der Unterscheidung der beiden Geschlechter der Canace ist Loew's Auffassung, Haliday gegenüber, die richtige; es ist das $q$, welches am Hinterleibsende zwei aufwärts ragende, kurzgedornte Zapfen führt; unter der (nicht sichtbaren) Legröhre sind noch zwei, äusserst kleine zweifachgedornte Zipfel wahrzunehmen.

In einem hochträchtigen $\uparrow$ (aus derselben Zeit) zählte ich an 20 recht grosse reife Eier, welche madenförmig gestreckt und blutröthlich angehaucht waren, ohne jedoch etwas von der Contour der werdenden Made erkennen zu lassen. - Andere Weibchen enthielten weniger reife, ungefärbtc Eier.

Das männliche Organ besteht in der Hauptsache aus einer bis an das dritte Leibessegment reichenden, etwas conischen Röhre und ist bis auf die äusserste, geknöpfte Spitze, welche sehr wenig zu Tage liegt, verborgen; die lappigen Arme der Haltezange sind wenig sichtbar und von gewöhnlicher Bildung.

\section{Nachträge zur Monographie der 0estriden.}

Von Prof. Dr. Friedr. Brauer.

\section{Zur Charakteristik und Verwandtschaft der Oestriden-Gruppen im Larven- und vollkommenen Zustande. *)}

Charakteristik der Oestriden-Larven im reifen $\mathrm{Zustande.}$

Da es mir gelungen ist Merkmale aufzufinden, wodurch sich die im Magen und Darm, in den Höhlen des Kopfes und die unter der Haut lebenden Oestriden-Larven in 2 Hauptabtheilungen und vier Gruppen stellen lassen, so gebe ich hier eine kurze Charakteristik der Larven aller Gattungen, ohne jedoch behaupten zu wollen, dass diese Anordnung durch die Entdeckung neuer Larvenformen nicht wieder einer Veränderung unterliegen könnte. Unter den bekannten Larven aber bildet keine eine Ausnahme und darum scheint mir diese Gruppirung eine natürliche zu sein und für die Verwandtschaft der in jeder

*) I. Siehe Wien. Entom. Zeitg. 1886, pag. 289. 


\section{$2 \mathrm{BHL}$ Biodiversity Heritage Library}

Reitter, Edmund. 1887. "Einige Beobachtungen über die Eigenart der Canace ranula LOEW." Wiener entomologische Zeitung 6, 1-4. https://doi.org/10.5962/bhl.part.17722.

View This Item Online: $\underline{\text { https://www.biodiversitylibrary.org/item/44060 }}$

DOI: https://doi.org/10.5962/bhl.part.17722

Permalink: https://www.biodiversitylibrary.org/partpdf/17722

\section{Holding Institution}

Smithsonian Libraries

\section{Sponsored by}

Smithsonian

\section{Copyright \& Reuse}

Copyright Status: NOT_IN_COPYRIGHT

This document was created from content at the Biodiversity Heritage Library, the world's largest open access digital library for biodiversity literature and archives. Visit BHL at https://www.biodiversitylibrary.org. 